\title{
Visita del profesor Dr. Giulio Maspero
}

\author{
Alejandro Nicola
}

El doctor Giulio Maspero visitó nuestra Facultad entre el 23 y el 29 de septiembre para participar en el Coloquio internacional sobre el vinculo entre espiritu y cuerpo según Gregorio de Nisa. El profesor Maspero es vicedecano de la Facultad de Teología de la Universidad de la Santa Cruz, en Roma, y miembro del equipo directivo de la Academia Pontificia de Teología. Se doctoró en Teología después de haberlo hecho en Física y de haberse dedicado por varios años a ese ámbito de las ciencias. Actualmente sus áreas de investigación son la teología trinitaria, Gregorio de Nisa y la relación entre filosofía y teología. Es además coeditor, junto a Lucas Francisco Mateo-Seco, del Diccionario de San Gregorio de Nisa.

Dictó una conferencia abierta en la que explicó que la comprensión de la relación entre el espíritu y el cuerpo permite entender la actualidad que tiene este tema socio-culturalmente. Al mundo contemporáneo no le basta la conside- ración intelectualista-abstracta de la realidad sino que necesita hacer experiencia de lo material-concreto. Desde el Verbo hecho carne la reflexión cristiana hace un aporte ineludible a la historia del pensamiento, subrayando el valor de lo corpóreo. A partir de esta perspectiva, señaló el profesor visitante que la relación entre el espíritu y el cuerpo es constitutiva del hombre, no se excluyen mutuamente. El pensamiento de los Padres Capadocios tomó elementos de la metafísica clásica a los que unió aportes de la Revelación para dar una ontología trinitaria que es una ontología de relación; ella permite entender mejor que en la sustancia divina haya relaciones no accidentales. Esto ayuda a plantear la distinción economía-inmanencia y la correlatividad entre las personas divinas. Este pensamiento influyó también sobre la filosofía griega ya que los conceptos introducidos por los Capadocios entraron en la discusión académica de la época. Concluyó su exposición diciendo 
que "las relaciones dentro del ser divino cambian las relaciones del ser creado" y que "a Dios le gusta ser hombre".

Participó también en dos sesiones de trabajo con profesores y alumnos de postgrado sobre la metodología y el estado actual de los estudios gregorianos, respectivamente. A partir de esa experiencia el profesor destacó la importancia que tiene el concepto y la experiencia de una comunidad académica. Ella permite seguir incorporando nuevas aproximaciones y no cerrarse de manera monolítica, facilitando así el progreso de los estudios. En cuanto a las líneas de investigación nisenas, señaló el académico, que hay temas todavía abiertos como el de la doble creación; la epéktasis; la apokatástasis; la apófasis; y la relación de su pensamiento con el platonismo y con el neoplatonismo. $\mathrm{Y}$ que hay otros temas que no han sido investigados como la libertad y el valor de lo creado; el aporte de su cristología y la evolución en su pensamiento.

Por otra parte el profesor reconoció la importancia que los estudios sobre Gregorio han tenido en esta Facultad de Teología como puede verse por las tesis de licencia y doctorado dedicados a su obra, por los seminarios de postgrado y por la dedicada labor de la profe- sora Hna. Anneliese Meis quien ha transmitido con muy buen método la riqueza de este Padre de la Iglesia.

El Dr. Maspero destacó la importancia que para complementar e integrar la labor académica tiene una dimensión pastoral que realizada con pasión sea capaz de seguir despertando el amor y el deseo que no tienen límites en su capacidad de crecimiento (epéktasis), engendrando vida y despertando nuevos discípulos para la comunidad académica.

Por fin participó en una mesa redonda con académicos de distintas disciplinas. Entre ellos la Dra. Patricia Moya, experta en la fenomenología de M. Merleau-Ponty; el Dr. Alejandro Serani en biofilosofía; el Dr. Rodrigo Polanco en la eclesiología de H. U. von Balthasar, y el Dr. Juan Fco. Pinilla, en la teología mística de Juan de la Cruz. Esta instancia dejó ver el valor integrador que tiene el saber académico cuando se abre a otras perspectivas. Así las ciencias biológicas y físicas proponen un dato concreto a analizar, ese dato trae la pregunta filosófico-metafísica que la teología intenta iluminar desde la revelación. Un ejercicio de diálogo respetuoso y de apertura supera prejuicios y dialécticas irreductibles. 
La presencia de académicos y coloquio que permite esperar una alumnos provenientes de otros paí- mayor colaboración entre los estuses como Argentina y Colombia diosos del pensamiento de Gregohan dado un matiz internacional al rio de Nisa en Latinoamérica. 
